\title{
Recurrent sterile meningitis caused by a pituitary abscess
}

\author{
J. Ford ${ }^{1}$, L.F. Torres ${ }^{2}$, T. Cox $^{3}$ and R. Hayward ${ }^{4}$ \\ Departments of ${ }^{1}$ Neurology, ${ }^{2}$ Neuropathology and ${ }^{4}$ Neurosurgery, The National Hospital, Queen Square, London \\ WC1N $3 B G$ and ${ }^{3}$ Department of Neuroradiology, Guy's Hospital, London SE1, UK.
}

\begin{abstract}
Summary: The case of a 21 year old woman who presented with recurrent sterile meningitis and bitemporal hemianopia is described. Computed tomographic scan showed a large low density ring enhancing lesion above and within the pituitary fossa which at operation and on histological examination was found to be compatible with an abscess. The visual field defect recovered completely and the scan appearances returned to normal postoperatively.
\end{abstract}

\section{Introduction}

Cystic lesions in the region of the pituitary fossa can occasionally present as recurrent meningitis. The most likely explanation is that the episodes of meningism are due to leakage of irritant contents (Bjerre et al., 1983). We describe a case of pituitary abscess with this presentation and discuss the origin and endocrine features of this lesion.

\section{Case report}

A 21 year old woman, born in England of Indian parents, was admitted to her local hospital in July 1984 with meningism. Lumbar puncture showed protein $1.6 \mathrm{~g} / \mathrm{l}$, glucose $1.8 \mathrm{mmol} / \mathrm{l}$, white cells $1.39 \times 10^{9} / 1$ (lymphocytes $98 \%$, neutrophils $2 \%$ ), fluid turbid, no acid-fast bacilli seen, no organisms isolated, viral studies negative; blood glucose $5.8 \mathrm{mmol} / 1$. A diagnosis of viral meningitis was made and she recovered with no treatment. Two weeks later she developed intermittent mild headache and blurred vision. Her menstrual period did not occur and she noticed increased thirst and frequency of micturition.

She was readmitted in September after 2 days of severe headache, vomiting and photophobia. She was febrile $\left(38.2^{\circ} \mathrm{C}\right)$, restless and disorientated, with a stiff neck and positive Kernig's sign. Lumbar puncture showed protein $0.54 \mathrm{~g} / 1$, glucose $2.6 \mathrm{mmol} / 1$ (blood glucose $4.6 \mathrm{mmol} / \mathrm{l}$ ), white cells $0.2 \times 10^{9} / 1$, lymphocytes $>90 \%$, no organisms were seen. Full blood count, electrolytes and chest X-ray were normal. It

Correspondence: L.F. Torres, M.D.

Accepted: 30 April 1986 was thought she might have tuberculous meningitis and she was started on rifampicin, isoniazid and ethambutol. The next day her temperature fell to normal and she was alert and orientated. Visual field examination demonstrated a bitemporal hemianopia. She was transferred to the National Hospital, Queen Square. She now had a low serum sodium $(128 \mathrm{mmol} /$ 1) and low plasma osmolality $(263 \mathrm{mmol} / \mathrm{kg})$ on intravenous infusion. At the time, plain X-ray of the pituitary fossa showed erosion of one side of the dorsum sellae, suggesting a suprasellar mass. High resolution computed tomographic (CT) scan (Figure 1) showed a low density mass within the sella and suprasellar cistern with a high density rim which enhanced with intravenous contrast. No calcification was seen. The pituitary fossa was large, but not grossly expanded. The radiological differential diagnosis was between a pituitary abscess, pituitary tumour with a necrotic centre, Rathke's cyst or an unusual craniopharyngioma. Endocrine investigations showed low $09.00 \mathrm{~h}$ cortisol $(<15 \mathrm{nmol} / \mathrm{l} ;$ normal $=170-720$ $\mathrm{nmol} / \mathrm{l})$, low free thyroxine $(5.6 \mathrm{pmol} / \mathrm{l}$; normal $=$ 8.8 $-25.7 \mathrm{pmol} / \mathrm{l})$ with thyroid stimulating hormone $<0.5 \mathrm{mU} / 1$, growth hormone $4.5 \mathrm{mU} / 1$ (normal $<10 \mathrm{mU} / \mathrm{l}$ ) and raised prolactin $1520 \mu \mathrm{U} / \mathrm{ml}$ (nor$\mathrm{mal}=118-508 \mu \mathrm{U} / \mathrm{ml})$. The anti-tuberculous chemotherapy was continued as it was thought the lesion could be a tuberculoma and high dose dexamethasone was added to decrease any local oedema contributing to pressure on the optic chiasma. At craniotomy 8 days later, a purple tumour was seen bulging between the optic nerves; aspiration produced a thick yellow fluid and biopsy specimens were taken. Laboratory examination of the fluid showed polymor- 


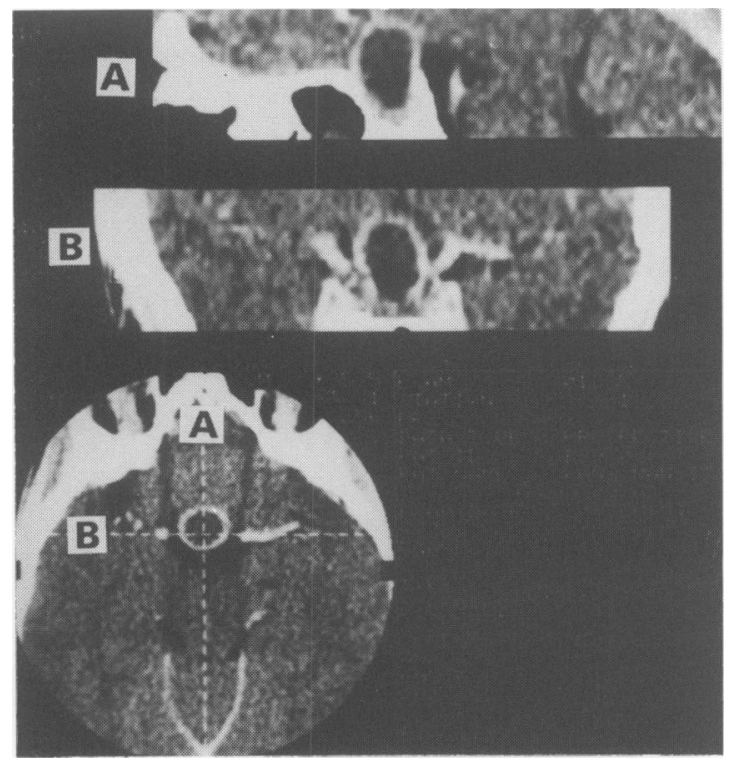

Figure 1 Postcontrast CT scan of the pituitary fossa and suprasellar region showing a low density lesion with ring enhancement. $A=$ saggital reconstruction; $B=$ coronal reconstruction.

phonuclear leucocytes and amorphous debris but no organisms (including tubercle bacilli) grew on culture. Histological examination showed three small fragments of dense collagenous tissue infiltrated by reactive plasma cells and a few lymphocytes, the former with slight pleomorphism and occasional binucleated forms; in some areas fibrin deposition, neutrophils and occasional macrophages were also present. The appearances were those of the capsule of an abscess (Figure 2). Normal residual anterior pituitary cells, although distorted by crush artefact, were also identified along one edge of the specimen. Immunocytochemical stainings for IgA, IgM and IgG were done and confirmed the reactive and polyclonal character of the plasma cell infiltrate (Figure 3). No evidence for pituitary adenoma, craniopharyngioma or Rathke's cyst were observed in any of the several histological sections studied.

Postoperatively she was given chloramphenicol, penicillin and metronidazole and made a good recovery. Her field defect resolved completely; 5 weeks later a control CT scan of the pituitary region showed no evidence of any residual mass. Pituitary function tests after 6 months showed a good growth hormone response to hypoglycaemia but impaired cortisol response. Thyrotrophin and luteinizing hormone releasing hormone tests were normal. Her prolactin had fallen after surgery. It remained normal 6 months postoperatively and she had spontaneously resumed regular menstruation.

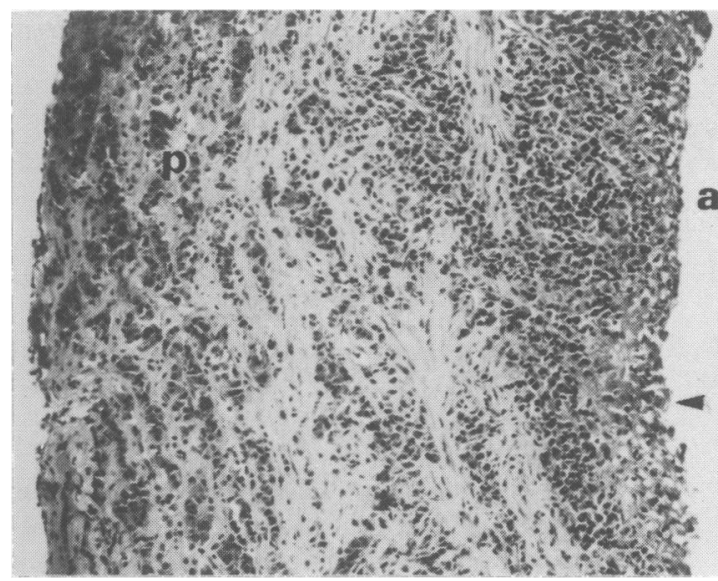

Figure 2 Section of abscess wall. Fibrin (arrow-head) lines the abscess cavity (a) and there is marked inflammatory cellular infiltration and fibrosis. Anterior pituitary tissue $(p)$ is also seen. $\mathrm{HE} \times 80$.

\section{Discussion}

Lesions of the pituitary or suprasellar region usually present with visual field defects, endocrine dysfunction or headache. Recurrent meningitis, although not common, can also be a presentation of some spaceoccupying lesions predominantly those with a cystic component such as craniopharyngioma, Rathke's cleft cyst, cystic degeneration of pituitary tumours and pituitary abscess.

Pituitary abscesses are rare, only some 50 cases have been reported. Most arise in apparently normal

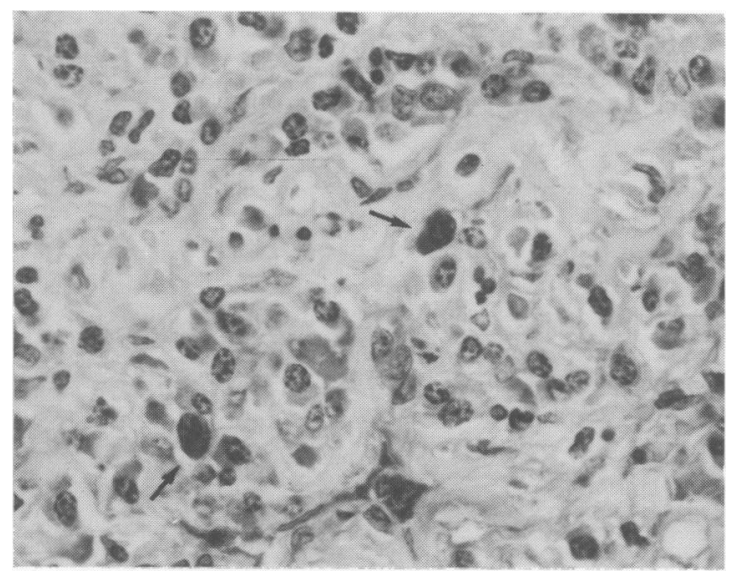

Figure 3 Section stained by the immuno-peroxidase technique to demonstrate IgM. The majority of cells in the inflammatory infiltrate are plasma cells, some of which are positively stained (arrows). $\times 400$. 
pituitary tissue but around $30 \%$ are associated with a pituitary adenoma, craniopharyngioma or Rathke's cyst (Lindholm et al., 1973; Domingue et al., 1977; Scanarini et al., 1980). At the time of diagnosis the majority of patients have a uni- or bi-temporal hemianopia, enlarged pituitary fossa and some endocrine dysfunction. A third of patients have meningitis, often more than one episode. Recurrent episodes of headache (sometimes with vomiting) are common and suggest meningism.

It has been suggested that the abscess is secondary to bacterial meningitis (Lindholm et al., 1973; Scanarini et al., 1980) but in our case the initial cerebrospinal fluid findings and recovery without therapy make this hypothesis unlikely. A better explanation would be that the episodes of meningism are due to leakage of irritant contents from the abscess (Bjerre et al., 1983). This hypothesis can also be applied to all the other cystic lesions mentioned above and therefore these should be considered early in the differential diagnosis of any patient presenting with recurrent meningism.

The origin of pituitary abscesses remains in dispute. A variety of major and minor pathogens have been grown from them but no organisms commonly implicated. In some cases antibiotics had been given preoperatively but in others the lesion was apparently sterile (Lindholm et al., 1973; Mohr, 1975; Scanarini et al., 1980). This, together with the long history of pituitary dysfunction often obtained has suggested

\section{References}

BJERRE, P., RIISHEDE, J. \& LINDHOLM, J. (1983). Pituitary abscess. Acta Neurochirurgica, 68, 187.

BLACKETT, P.R., BAILEY, J.D. \& HOFFMAN, H.J. (1980). A pituitary abscess simulating an intrasellar tumor. Surgical Neurology, 14, 129.

DOMINGUE, J.N. \& WILSON, C.B. (1977). Pituitary abscesses. Report of seven cases and review of the literature. Journal of Neurosurgery, 46, 601.

FRANKS, S. \& JACOBS, H.S. (1983). Hyperprolactinaemia. Clinics in Endocrinology and Metabolism (London), 12, 641. that they are not infective, but are due to necrosis of a pituitary adenoma (Bjerre et al., 1983). In the present case this can be excluded on histological grounds.

The endocrinological picture was one of pituitary stalk or hypothalamic compression. The prolactin was raised to a level consistent with deficiency of prolactin inhibitory factor (Franks \& Jacobs, 1983) and other pituitary hormones were depressed. After the operative relief of the compression the prolactin fell to normal and other pituitary functions improved. The patient had preoperative symptoms of diabetes insipidus which is commonly observed in lesions of the pituitary stalk and median eminence. The frequent concurrence of failure of menstruation (likely to be secondary to hyperprolactinaemia) and diabetes insipidus (Blackett et al., 1980) in patients with pituitary abscess suggests that hypothalamic or pituitary stalk compression may be a more common mechanism of functional disturbance in these cases than direct destruction of pituitary tissue.

\section{Acknowledgements}

We thank Professor L.W. Duchen, Dr S. Franks and Dr P. Kennedy for encouragement and helpful discussion; Professor J. Marshall for allowing us to present his patient and for reviewing the manuscript; $\mathrm{Mr} \mathbf{R}$. Brooks for printing the illustrations. L.F.T. is in receipt of a fellowship from C.N. Pq - Brazil.
LINDHOLM, J., RASMUSSEN, P. \& KORSGAARD, O. (1973). Intra-sellar or pituitary abscess. Journal of Neurosurgery, 38, 616.

MOHR, P.D. (1975). Hypothalamic-pituitary abscess. Postgraduate Medical Journal, 51, 468.

SCANARINI, M., CERVELLINI, P., RIGOBELLO, L. \& MINGRINO, S. (1980). Pituitary abscesses: report of two cases and review of the literature. Acta Neurochirurgica, 51, 209. 